\title{
Diversity of family GH46 chitosanases in Kitasatospora setae KM-6054
}

\author{
Mina Zitouni $^{1} \cdot$ Pascal Viens $^{1,2} \cdot$ Mariana G. Ghinet ${ }^{1,3} \cdot$ Ryszard Brzezinski $^{1}$ (D)
}

Received: 8 June 2017 /Revised: 18 August 2017 / Accepted: 5 September 2017 / Published online: 18 September 2017

(C) The Author(s) 2017. This article is an open access publication

\begin{abstract}
The genome of Kitasatospora setae KM-6054, a soil actinomycete, has three genes encoding chitosanases belonging to GH46 family. The genes (csn1-3) were cloned in Streptomyces lividans and the corresponding enzymes were purified from the recombinant cultures. The $\operatorname{csn} 2$ clone yielded two proteins ( $\mathrm{Csn} 2 \mathrm{BH}$ and $\mathrm{Csn} 2 \mathrm{H}$ ) differing by the presence of a carbohydrate-binding domain. Sequence analysis showed that Csn1 and Csn2H were canonical GH46 chitosanases, while Csn 3 resembled chitosanases from bacilli. The activity of the four chitosanases was tested in a variety of conditions and on diverse chitosan forms, including highly $\mathrm{N}$ deacetylated chitosan or chitosan complexed with humic or polyphosphoric acid. Kinetic parameters were also determined. These tests unveiled the biochemical diversity among these chitosanases and the peculiarity of Csn 3 compared with the other three enzymes. The observed biochemical diversity is discussed based on structural 3D models and sequence alignment. This is a first study of all the GH46 chitosanases produced by a single microbial strain.
\end{abstract}

Mina Zitouni and Pascal Viens contributed equally to this work.

Ryszard Brzezinski

Ryszard.Brzezinski@USherbrooke.ca

1 Centre d'Étude et de Valorisation de la Diversité Microbienne; Département de Biologie; Faculté des Sciences, Université de Sherbrooke, 2500, boul.de l'Université, Sherbrooke, Québec J1K 2R1, Canada

2 Present address: Innomalt Inc, Sherbrooke, Québec, Canada

3 Present address: Département de Pharmacologie, Faculté de Médecine et des Sciences de la Santé, Université de Sherbrooke, Sherbrooke, Québec, Canada
Keywords Chitosan · Chitosanase - Kitasatospora . Actinomycetes $\cdot$ Glycoside hydrolase $\cdot$ Genome mining

\section{Introduction}

Chitosan is a polymeric amino sugar composed of a majority of D-glucosamine $(\mathrm{GlcN})$ units and a minority of $N$-acetyl-Dglucosamine units (GlcNAc) united by $\beta$-1,4-glycosidic links. The degree of $N$-deacetylation (DDA), an important parameter determining the chemical and biological behavior of chitosan, is defined as the proportion of GlcN groups in a given sample of chitosan (Roberts 1992). Chitosan is present in the cell walls of several groups of microorganisms, like Zygomycetes fungi or microalgae (Bartnicki-Garcia 1968, Kapaun and Reisser 1995). Starting from raw materials containing chitin, such as crustacean shells (essentially shrimps and crabs), chitosan is produced at an industrial scale by alkaline treatment. Chitosan has numerous potential applications in medicine and technology, which justifies its production at the level of hundreds of tons per year (Hamed et al. 2016).

Chitosan is chemically more reactive than most polysaccharides due to the free amino groups, which are deprotonated at mildly acidic $\mathrm{pH}$ (the isoelectric point of chitosan is around 6.2). Considering the complexity of the constituents of natural environments, chitosan could be present in a wide variety of forms: more or less $\mathrm{N}$-deacetylated, in a protonated or deprotonated form (depending on surrounding $\mathrm{pH}$ ), forming salts with environmental acids, chelating metals, or complexed with polymers. However, chitosan was rarely considered in ecological studies.

Chitosan can be hydrolyzed by endo-hydrolases as chitosanases, chitinases, or lysozymes which activity often depends on the DDA of chitosan (Hoell et al. 2010). The hydrolysis, initiated by these endo-acting enzymes and 
resulting in dimeric or longer products, can be completed by exo-acting enzymes like glucosaminidases and $N$-acetylglucosaminidases, generating, respectively, GlcN and GlnNAc monomers. All these enzymes are widely represented in living organisms (Hoell et al. 2010).

Chitosans with moderate or high DDA values are preferentially hydrolyzed by chitosanases. The best characterized chitosanases belong to families GH46, GH8, and GH80 of glycoside hydrolases and their catalytic mechanisms as well as structure-function relationships were described in great detail, essentially due to crystallographic and site-directed mutagenesis studies (Adachi et al. 2004, Liu et al. 2015, Viens et al. 2015b, Yorinaga et al. 2017). However, almost all chitosanase studies have been dedicated to only one enzyme per microbial strain. Multiple chitosanases originating from a single microbial strain were rarely reported. Therefore, it remains largely unknown how a single bacterial species deals with the wide variety of chitosan forms potentially present in nature.

Pelletier and Sygusch (1990) isolated a strain of Bacillus megaterium from soil and characterized three chitosanases (named A, B, and C) produced by this strain. All were acting as endo-hydrolases. They differed by their relative abundance in culture supernatant, their dependence of their activity on DDA of chitosan substrate, their specific activity against high-DDA chitosan, and their capacity to hydrolyze cellulosic substrates. While limited to biochemical aspects, this study revealed for the first time that a single bacterial species could produce several chitosanases, each with different properties.

In Aspergillus oryzae IAM2660, a mold used in the production of fermented food in Japan, three chitosanase genes ( $\operatorname{csn} A, B$, and $C$ ) belonging to GH75 family have been cloned and sequenced but only the chitosanase CsnC was characterized in detail (Zhang et al. 2000; Sugita et al. 2012). This chitosanase is atypical as it includes three tandem-repeated peptides forming the so-called $\mathrm{R} 3$ domain at the $\mathrm{C}$-terminus. This domain had the ability to bind to insoluble chitosan but did not influence significantly the enzyme activity.

Three genes encoding putative GH46 chitosanases have been detected in the genomic sequence of Streptomyces sp. SirexAA-E (Takasuka et al. 2014). Only one chitosanase, SACTE 5457 has been studied in detail (including 3Dstructure determination following crystallization) as the proteins encoded by the other two genes could not be detected in any of the tested culture conditions. Finally, two chitosanases were detected in the chitosan-assimilating strain Acinetobacter sp. CHB101 (Shimosaka et al. 1995). These enzymes differed essentially by their substrate preference, chitosanase II being able to hydrolyze efficiently glycol chitin as well as $70 \%$-deacetylated chitosan, while chitosanase I preferred highly deacetylated chitosan.

Exploring the carbohydrate active enzymes database (www.cazy.org) (Lombard et al. 2014), we identified
Kitasatospora setae KM-6054 as one strain having three genes encoding putative chitosanases belonging to GH46 family. We present in this work for the first time an exhaustive comparative study of all the GH46 chitosanases encoded by a single strain; furthermore, we compare two forms of the same enzyme encoded by one of the chitosanase genes. Finally, we discuss the molecular basis of the observed biochemical diversity.

\section{Materials and methods}

\section{Bacterial strains}

Kitasatospora setae KM-6054 (Ōmura et al. 1981) was obtained from the microbial collection of the Kitasato University, Tokyo, Japan (also available as ATCC 33774). Escherichia coli DH5 $\alpha$ (Hanahan 1985) was used for plasmid propagation. Streptomyces lividans TK24 $\Delta c s n R$ (formerly $\Delta 2657$ h) (Dubeau et al. 2011a; Brzezinski 2011) was used as host for recombinant plasmids directing chitosanase production.

\section{Media and culture conditions}

Luria-Bertani (broth or agar) medium was used for all manipulations involving E. coli (Hanahan 1985). Routine propagation of $K$. setae was done on yeast-malt extract (YME) medium (glucose, $4 \mathrm{~g} \mathrm{~L}^{-1}$; yeast extract, $4 \mathrm{~g} \mathrm{~L}^{-1}$; malt extract, $\left.10 \mathrm{~g} \mathrm{~L}^{-1}\right)$.

Native and recombinant $S$. lividans TK24 $\Delta c s n R$ strains were grown on tryptic soy broth (TSB) or tryptic soy agar (TSA). Spores of S. lividans were collected after heavy inoculation of oatmeal agar plates followed by 1 week of incubation. Incubation of $E$. coli or actinobacterial strains on all media was at 37 or $30^{\circ} \mathrm{C}$, respectively. All media components were from Difco Laboratories.

\section{Construction of recombinant plasmids}

All the genetic constructions were performed using the shuttle vector pFDES, a derivative of pFD666 obtained after deleting a segment delimited by unique NruI and AclI sites (Sanssouci et al. 2011). All plasmids have been constructed and propagated using $E$. coli, and the final constructions were transformed into $S$. lividans TK24 $\Delta c s n R$. The genes were amplified from genomic DNA by PCR using primers listed in Table 1. Amplicons for $\operatorname{csn} 1$ and $\operatorname{csn} 2$ genes were digested with HindIII and ScaI and ligated to pFDES vector digested with the same restriction enzymes. For $\operatorname{csn} 3$, a synthetic DNA segment (containing the transcription promoter and the ribosome-binding site) digested with HindIII and NdeI was ligated with the $\operatorname{csn} 3$-amplicon digested with $N d e \mathrm{I}$ and 
Table 1 Primers and synthetic DNA used for chitosanase gene cloning

\begin{tabular}{|c|c|c|c|}
\hline Name & Sequence $\left(5^{\prime}-3^{\prime}\right)$ & $\begin{array}{l}\text { Coordinates of homologous } \\
\text { genomic segment covered } \\
\text { by the primer }\end{array}$ & $\begin{array}{l}\text { Length of amplified } \\
\text { genomic segment }\end{array}$ \\
\hline $\begin{array}{l}\text { Forward Csn } 1 \\
\text { Reverse Csn1 }\end{array}$ & $\begin{array}{l}\text { NNNNNNNNNNAAGCTTCCGGATGCCGTCAGACGT } \\
\text { NNNNNNNNNNAGTACTGTCCGTCAGCGAAGCGAA }\end{array}$ & $\begin{array}{l}1,679,152-1,679,135 \\
1,678,052-1,678,069\end{array}$ & $1101 \mathrm{bp}$ \\
\hline $\begin{array}{l}\text { Forward Csn2 } \\
\text { Reverse Csn2 }\end{array}$ & $\begin{array}{l}\text { NNNNNNNNNNAAGCTTCCTGATGGTCGGTCATC } \\
\text { NNNNNNNNNNAGTACTGCGGAGACCCGTTCGTTA }\end{array}$ & $\begin{array}{l}4,542,402-4,542,421 \\
4,543,987-4,543,970\end{array}$ & $1586 \mathrm{bp}$ \\
\hline $\begin{array}{l}\text { Forward csn3 } \\
\text { Reverse csn3 }\end{array}$ & $\begin{array}{l}\text { TTCGCAAGGAGAACCATATGCGC } \\
\text { NNNNNNNNNNGGATCCACCACTCCGTGCAATGGAAC }\end{array}$ & $\begin{array}{l}4,551,090-4,551,112 \\
4,552,052-4,552,032\end{array}$ & $988 \mathrm{bp}$ \\
\hline $\begin{array}{l}\text { Synthetic DNA } \\
\text { (promoter and RBS for csn3) }\end{array}$ & $\begin{array}{l}\text { AAGCTTGAATTCAATTGCCCACTTGACGTTGAGAGT } \\
\text { GAAGCAATATAGGTTAACCTCGGTTCGAAACCAGG } \\
\text { AGACGTACATATG }\end{array}$ & & \\
\hline
\end{tabular}

Restriction sites used for cloning are underlined. Bold characters in the synthetic DNA sequence indicate the -35 and -10 boxes of the promoter sequence D1-7 as identified by Seghezzi et al. (2011)

BamHI and the pFDES vector digested with HindIII and BamHI. Synthetic DNA (Table 1) was obtained from Biomatik (Cambridge, Ontario, Canada). Amplification of gene segments was performed with Q5 Hot Start High Fidelity polymerase (New England BioLabs, Ipswich, MA, USA) after primer/DNA annealing at $69{ }^{\circ} \mathrm{C}(\operatorname{csn} 1$ and $\operatorname{csn} 3)$ or $66^{\circ} \mathrm{C}(\operatorname{csn} 2)$. DNA primers were obtained from Integrated DNA Technologies (Coralville, IA, USA).

\section{Chitosanase production and purification}

Spores of S. lividans $\Delta c s n R$ harboring the recombinant plasmids were inoculated into TSB medium supplemented with $50 \mu \mathrm{g} \mathrm{mL}^{-1}$ kanamycin, and the cultures were incubated for $48 \mathrm{~h}$ at $30^{\circ} \mathrm{C}$ with shaking $\left(230 \mathrm{rpm} \mathrm{min}^{-1}\right)$. Mycelium was recovered by low-speed centrifugation and inoculated in a modified M14 medium (Pagé et al. 1996): composed of $\mathrm{KH}_{2} \mathrm{PO}_{4}, 1 \mathrm{~g} \mathrm{~L}^{-1} ; \mathrm{K}_{2} \mathrm{HPO}_{4}, 5 \mathrm{~g} \mathrm{~L}^{-1} ; \mathrm{NH}_{4} \mathrm{Cl}, 1 \mathrm{~g} \mathrm{~L}{ }^{-1}$; $\mathrm{K}_{2} \mathrm{SO}_{4}, 1 \mathrm{~g} \mathrm{~L}^{-1}$; and $1 \mathrm{ml} \mathrm{L}^{-1}$ of trace elements solution $\left(\mathrm{CoCl}_{2} \cdot 7 \mathrm{H}_{2} \mathrm{O}, 2 \mathrm{mg} \mathrm{mL}{ }^{-1} ; \mathrm{FeSO}_{4} \cdot 7 \mathrm{H}_{2} \mathrm{O}, 5 \mathrm{mg} \mathrm{mL}^{-1}\right.$; $\mathrm{MnSO}_{4} \cdot \mathrm{H}_{2} \mathrm{O}, 1.6 \mathrm{mg} \mathrm{mL}{ }^{-1}$, and $\mathrm{ZnSO}_{4} \cdot 7 \mathrm{H}_{2} \mathrm{O}$, $\left.1.4 \mathrm{mg} \mathrm{mL}^{-1}\right)$, $\mathrm{pH}$ 6.9. After autoclaving, $\mathrm{MgSO}_{4}, 0.3 \mathrm{~g} \mathrm{~L}^{-1}$ and $\mathrm{CaCl}_{2}, 0.3 \mathrm{~g} \mathrm{~L}^{-1}$ were added to the M14 medium. The resulting mineral solution was supplemented with $10 \mathrm{~g} \mathrm{~L}^{-1}$ mannitol as carbon source. Cultures were incubated at $30^{\circ} \mathrm{C}$ with shaking (230 rpm $\mathrm{min}^{-1}$ ). Incubation time was $48 \mathrm{~h}$ for Csn 1 and Csn 2 and $70 \mathrm{~h}$ for Csn3. For enzyme purification, culture supernatants were recovered after low-speed centrifugation $\left(20 \mathrm{~min}, 4000 \mathrm{~g}\right.$ at $\left.4{ }^{\circ} \mathrm{C}\right)$.

Csn1 was purified using a procedure previously published for chitosanase from Streptomyces sp. N174 without modifications (Lacombe-Harvey et al. 2009).

For Csn2 isoforms (Csn2BH and $\mathrm{Csn} 2 \mathrm{H})$ purification, the culture supernatant was adjusted to $\mathrm{pH} 7.5$ with Tris base, then diluted with distilled water to attain a conductivity of $4 \mathrm{mS} \mathrm{cm}^{-1}$ and loaded on a Q-XL Sepharose column (GE
Healthcare) equilibrated with $20 \mathrm{mM}$ Tris- $\mathrm{HCl}$ buffer $\mathrm{pH}$ 7.5. Elution was performed with $0-0.6 \mathrm{M} \mathrm{NaCl}$ gradient in the same buffer. Active fractions were pooled, dialyzed against unbuffered $1 \mathrm{mM} \mathrm{MgCl}_{2}$, and loaded on Hydroxyapatite Fast Flow (Calbiochem) column $(8 \times 1.6 \mathrm{~cm})$ pre-equilibrated with unbuffered $1 \mathrm{mM} \mathrm{MgCl} 2$. Elution was performed with five column volumes unbuffered

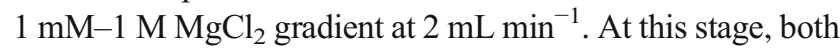
$\mathrm{Csn} 2$ forms were coeluted. To separate Csn2BH from $\mathrm{Csn} 2 \mathrm{H}$, chitosanase active fractions were pooled, dialyzed against $20 \mathrm{mM}$ Tris- $\mathrm{HCl}+150 \mathrm{mM} \mathrm{NaCl}$, and then loaded onto a size exclusion Sephacryl S-100 HR column $(80 \times 1.6 \mathrm{~cm})$ equilibrated with the same buffer and eluted under gravity.

For Csn3 purification, the culture supernatant was adjusted to $\mathrm{pH} 8$ with Tris base, then diluted with distilled water to attain a conductivity of $4 \mathrm{mS} \mathrm{cm}^{-1}$ and loaded on a Q-XL Sepharose column equilibrated with $20 \mathrm{mM}$ Tris- $\mathrm{HCl} \mathrm{pH} 8$. Elution was performed with $0-0.6 \mathrm{M} \mathrm{NaCl}$ gradient in the same buffer. Active fractions were pooled, dialyzed against unbuffered $1 \mathrm{mM} \mathrm{MgCl}$, and loaded on Hydroxyapatite Fast Flow column $(5 \times 1.6 \mathrm{~cm})$ pre-equilibrated with unbuffered $1 \mathrm{mM} \mathrm{MgCl}_{2}$. The column was washed with unbuffered $1 \mathrm{M} \mathrm{MgCl}_{2}$, then with $10 \mathrm{mM}$ potassium phosphate $\mathrm{pH} 6.8$. Elution was performed with a $10-300 \mathrm{mM}$ potassium phosphate buffer $\mathrm{pH} 6.8$ gradient.

All four purified enzyme preparations were dialyzed against $50 \mathrm{mM}$ Na-acetate buffer $\mathrm{pH} 5.5$ and stored at $4{ }^{\circ} \mathrm{C}$. They were supplemented with $50 \%$ glycerol for long-term storage at $-20^{\circ} \mathrm{C}$.

\section{Biochemical assays}

The purity of the enzyme preparations was evaluated by SDSPAGE (Laemmli 1970) using the PageRuler Protein Ladder (Thermo Fisher Scientific, Waltham, MA, USA) as molecular weight standard. Protein concentration was determined by the 
method of Bradford (1976) using bovine serum albumin as standard (Sigma). Protein concentration of purified chitosanases was determined by ultraviolet absorbance $(280 \mathrm{~nm})$ using the following molar extinction coefficients (in $\mathrm{M}^{-1} \mathrm{~cm}^{-1}$ ): 32890 for Csn1, 76320 for Csn2BH, 35410 for $\mathrm{Csn} 2 \mathrm{H}$, and 25440 for Csn3. The coefficients were estimated from amino acid sequences using the ProtParam tool on ExPASy server (Gasteiger et al. 2005) following the rules established by Gill and von Hippel (1989). To determine the exact $\mathrm{N}$-termini for $\mathrm{Csn} 2 \mathrm{BH}$ and $\mathrm{Csn} 2 \mathrm{H}$, a proteomic analysis was performed by Plateforme Protéomique (Centre de Génomique de Québec, Université Laval, Québec, QC, Canada).

Chitosanase activity was assayed by two methods. Rapid assay in culture supernatants and fractions eluted from chromatographic columns was performed using the soluble chitosan derivative sRBB-C as substrate (Zitouni et al. 2010). For all other experiments, chitosanase activity was measured by the release of reducing sugars from chitosan substrate with Dglucosamine as standard by the method of Lever (1972), using the $p$-hydroxybenzoic acid (PAHBAH) reagent as modified by Schep et al. (1984). Readings of optical density at $405 \mathrm{~nm}$ were performed on $200 \mu \mathrm{l}$ aliquots of reaction supernatant in 96 well plates using an Asys UVM 340 microplate reader (UK Biochrom). One unit of chitosanase was defined as the enzyme quantity which releases $1 \mu \mathrm{mol}$ of D-glucosamine equivalent per min from standard chitosan substrate in a 10 -min reaction at $37^{\circ} \mathrm{C}$.

The standard substrate solution was prepared with commercial chitosan obtained from Sigma-Aldrich, dissolved at $10 \mathrm{~g} \mathrm{~L}^{-1}$ in $0.2 \mathrm{M}$ acetic acid (stock solution), and diluted to a final concentration of $0.5 \mathrm{mg} \mathrm{mL}^{-1}$ in $50 \mathrm{mM}$ Na-acetate buffer $\mathrm{pH}$ 5.5. For kinetic experiments, the same stock solution was diluted toward concentrations ranging from 0.01 to $0.15 \mathrm{mg} \mathrm{mL}^{-1}$. To test the dependence of activity on the degree of deacetylation of substrate, solutions of chitosans deacetylated at 84.6 and $98.4 \%$ (Marinard, Québec) were prepared in the same way.

For the tests at low temperatures or in the presence of humic acids or polyphosphoric acid, all the chitosanase samples were first diluted in $50 \mathrm{mM} \mathrm{Na}$-acetate buffer $\mathrm{pH} 5.5$ in order to give approximatively the same release of reducing sugars in a standard assay for $10 \mathrm{~min}$ at $37{ }^{\circ} \mathrm{C}$ with standard chitosan substrate. This activity was taken as a reference (100\%) for comparison with the other conditions tested. For tests at low temperatures, the aliquoted standard substrate solution $(480 \mu \mathrm{L})$ was equilibrated at a given temperature before the addition of enzyme solution $(20 \mu \mathrm{L})$. Reactions were incubated for $20 \mathrm{~min}$ (for temperatures of $30,25,20$, and $15^{\circ} \mathrm{C}$ ) or $30 \mathrm{~min}$ (for temperatures of 10 and $7^{\circ} \mathrm{C}$ ) and stopped by the addition of $500 \mu \mathrm{L}$ of PAHBAH reagent.

The polyphosphoric acid-chitosan substrate was prepared as follows. Polyphosphoric acid liquid concentrate (Sigma-
Aldrich C3646) was diluted up to $1 \mathrm{mg} \mathrm{mL}^{-1}$ in Na-acetate buffer ( $\mathrm{pH} 4.5$ or 5.5 ). The chitosan component was prepared in the same buffer at $1 \mathrm{mg} \mathrm{mL}^{-1}$. To prepare $480 \mu \mathrm{L}$ of substrate, $120 \mu \mathrm{L}$ of buffered polyphosphoric acid solution was combined with $240 \mu \mathrm{L}$ of chitosan solution and completed with $120 \mu \mathrm{L}$ of Na-acetate buffer at the appropriate $\mathrm{pH}$. The combined substrates were kept overnight at room temperature and then incubated for $10 \mathrm{~min}$ at $37^{\circ} \mathrm{C}$ before addition of the enzyme. Reaction time was $100 \mathrm{~min}$.

For tests of activity in the presence of humic acids, the humic acid powder (Agros Organics AC120861000) was combined with $50 \mathrm{mM} \mathrm{Na}$-acetate buffer ( $\mathrm{pH} 4.5$ or 5.5 ) to the final concentration of $2 \mathrm{mg} \mathrm{mL}^{-1}$. The chitosan solution was also prepared at a concentration of $2 \mathrm{mg} \mathrm{mL}^{-1}$ in the same buffer. To prepare $480 \mu \mathrm{L}$ of substrate, $185 \mu \mathrm{L}$ of humic acid solution was combined with $125 \mu \mathrm{L}$ of chitosan solution and completed with Na-acetate buffer of appropriate $\mathrm{pH}$. The combined substrates were kept overnight at room temperature and then incubated for $10 \mathrm{~min}$ at $37{ }^{\circ} \mathrm{C}$ before addition of the enzyme. Reaction time was $10 \mathrm{~min}$ at $\mathrm{pH} 4.5$ and $15 \mathrm{~min}$ at $\mathrm{pH}$ 5.5.

Undissolved (suspended) chitosan substrate was prepared by adding $50 \mathrm{mg}$ of chitosan from Sigma-Aldrich to $10 \mathrm{ml}$ of $50 \mathrm{mM} \mathrm{Na}$-acetate buffer $\mathrm{pH}$ 5.5. The suspension was mixed by vortexing then kept $30 \mathrm{~min}$ at room temperature. Chitosan was recovered by centrifugation $(20 \mathrm{~min}$ at $4000 \mathrm{~g}$ then the pellet was suspended in $50 \mathrm{ml}$ of the same buffer, and vortexed and used immediately for reaction with enzyme (30 $\mathrm{min}$ at $37^{\circ} \mathrm{C}$ in a rotary agitator).

All reactions with chitosan/acid mixtures and undissolved chitosan were done in six independent replicas. Results were analyzed by the statistical Tukey's multiple comparisons test using GraphPad Prism software version 7.01.

\section{Results}

\section{Kitasatospora setae genome mining and rationale of gene cloning}

The CAZy database reveals three GH46 family genes in the genome of $K$. setae KM-6054; the first Kitasatospora genome to be entirely sequenced (Ichikawa et al. 2010). The $\operatorname{csn} 1$ gene (= KSE_15150) encodes a chitosanase (Csn1) whose primary sequence is rather similar to other well studied enzymes such as the chitosanases CsnN174 from Streptomyces sp. N174 and OU01 from Microbacterium sp., as illustrated by the alignments and trees presented by Takasuka et al. (2014) and Viens et al. (2015b). The csn1 gene forms most probably a monocistronic transcription unit, being flanked by a putative transcription terminator and a gene transcribed in an opposite direction (Fig. 1a). 


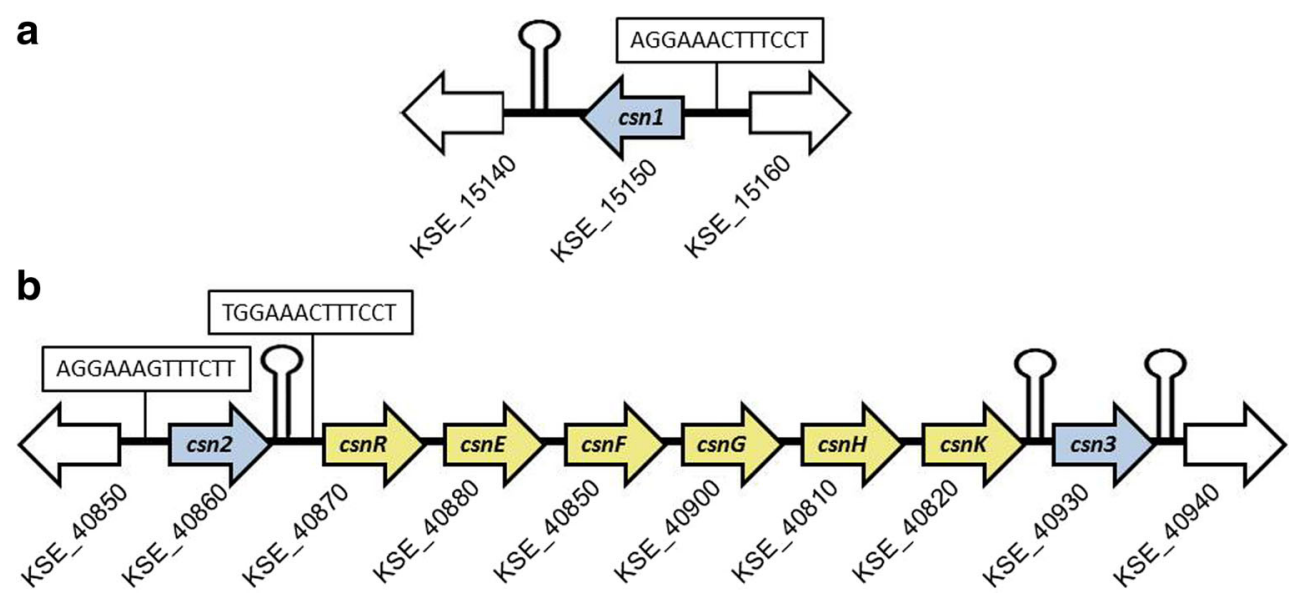

Fig. 1 Arrangement of GH46 chitosanase genes in the genome of $K$. setae. Gray arrows: chitosanase genes. Yellow arrows: genes belonging to a putative glucosamine oligosaccharide transport operon (Viens et al. 2015a). White arrows: flanking genes. The numbers of the genes from GenBank sequence file are also indicated. $\operatorname{csnR}$ : chitosanase gene repressor; $c s n E F G$ : $\mathrm{ABC}$ transporter; $c s n H$ : GH4 family glycoside hydrolase; and $c s n K$ : putative oligosaccharide kinase. Boxed sequences: putative operators recognized by $\mathrm{CsnR}$ repressor: stem and loops: putative palindromic terminators of transcription
Interesting features were found for the other two GH46 genes/proteins (Fig. 1b). The $\operatorname{csn} 2$ and $\operatorname{csn} 3$ genes are localized on both sides of a six-gene cluster led by an ortholog of $\operatorname{csn} R$, which we described previously (Dubeau et al. 2011b; Viens et al. 2015a). While this gene cluster, dedicated to the regulation of chitosanase gene expression and the transport of GlcN oligosaccharides resulting from chitosanase hydrolysis, is highly conserved in actinobacterial genomes, this is the first reported case where this cluster is accompanied by flanking chitosanase genes.

The chitosanases encoded by these genes also proved to be unusual among GH46 members. The Csn2 is distinctive because of the presence of a carbohydrate-binding module (CBM) between the signal peptide and the hydrolytic module, which is rare in GH46 family. Identified in protein databases as the F5_F8_type_C domain (pfam00754) or CBM32, the CBM present in Csn2 is highly similar to two domains, DD1 and DD2 (46 and 45\% of identity; 63 and $61 \%$ of similarity, respectively), present in the GH8 chitosanase from Paenibacillus sp. IK-5 and shown to function as binding modules specific to chitosan (Shinya et al. 2013). Otherwise, the hydrolytic module of Csn2 is similar to Csn1 and CsnN174 (Viens et al. 2015b).

Chitosanase Csn3 belongs to group B inside GH46 family, as defined by Viens et al. (2015b). Members of this group are frequent in bacilli but rare in actinobacteria and, according to the CAZy database, K. setae in one of only a few actinobacteria in which such a chitosanase is present.

To determine the cloning strategy, we analyzed upstream and downstream sequences from each ORF. When found, putative downstream transcription terminators of the "stem and loop type" (Fig. 1) were included in the segments amplified by PCR from genomic DNA. Putative transcription promoters were found in the upstream segments of $\operatorname{csn} 1$ and $\operatorname{csn} 2$ genes and were also included in the amplicons. As a consequence, these two amplified segments also included palindromic sequences localized between the putative promoter and the ribosome-binding site, and representing, most probably, the operators for binding of the repressor CsnR (Fig. 1), suggesting that these two genes were negatively regulated in a mode analogous to the one described for S. lividans (Dubeau et al. 2011a, b). As these operators were almost identical with those found in S. lividans, the negative regulation could be kept in this heterologous host, making the expression of $\operatorname{csn} 1$ and $\operatorname{csn} 2$ dependent on the presence of chitosan in the medium. To avoid this, the recombinant genes were transformed into an S. lividans host with deleted $c s n R$ gene (Dubeau et al. 2011a, Brzezinski 2011). In the case of $\operatorname{csn} 3$, we could not identify any sequence similar to a known actinobacterial promoter in the upstream segment. Thus, in the recombinant construction, a synthetic DNA segment including the strong promoter D1-7 (Seghezzi et al. 2011) and a ribosome-binding site was ligated to the amplified ORF (Table 1), providing the necessary elements for initiation of transcription and translation.

\section{Protein production and purification}

For chitosanase production, the recombinant strains were cultivated in a defined medium, containing only inorganic salts and mannitol as carbon source. Chitosanases were purified to apparent homogeneity (Fig. 2). During the purification of Csn2, it became apparent that the enzyme was present in two forms differing by their molecular weight. Both forms had largely coinciding peaks in the early steps of purification but could be separated by size-exclusion chromatography. Proteomic analysis was undertaken to confirm the identity of both purified polypeptides. It showed that the high-molecular 


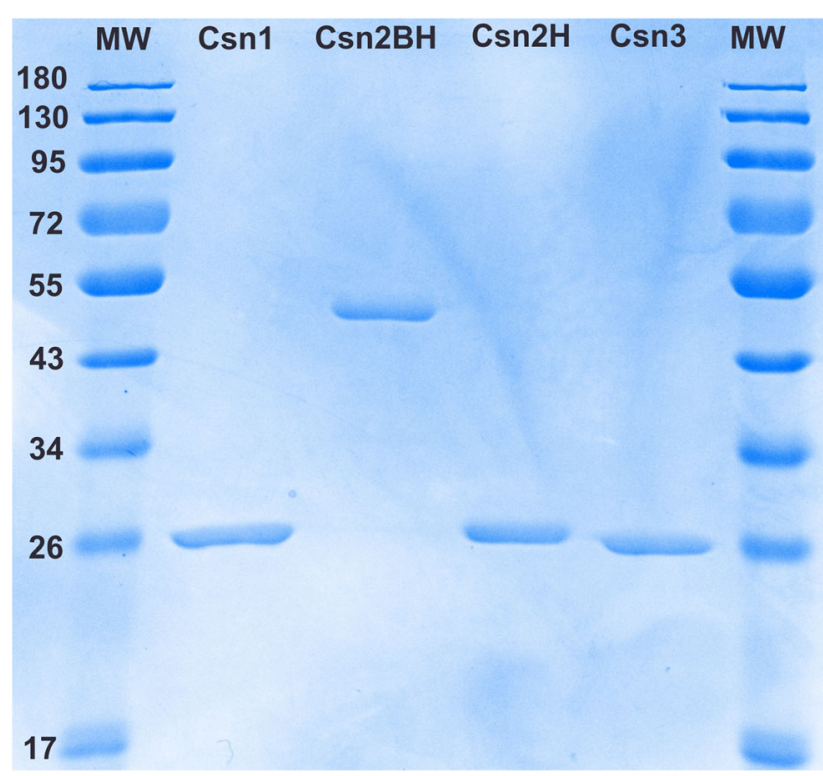

Fig. 2 SDS-PAGE analysis of purified chitosanases. MW molecular weight marker

weight polypeptide represented the full-length mature protein, containing both the carbohydrate-binding module at $\mathrm{N}$ terminus and the hydrolytic module at the C-terminus, while the low-molecular weight polypeptide included only the hydrolytic module. The polypeptides were named $\mathrm{Csn} 2 \mathrm{BH}$ and $\mathrm{Csn} 2 \mathrm{H}$, respectively. We also learned that $\mathrm{Csn} 2 \mathrm{H}$ was generated from $\mathrm{Csn} 2 \mathrm{BH}$ by cleavage in a Ser-Ala-Pro-rich segment, more precisely at the following site: TASASASA $\downarrow$ SPTASPSP.

The following specific activities (in units per milligram of protein) were determined for the purified enzymes by standard assay with chitosan Sigma: 19.2 for Csn1, 12.6 for Csn2BH, 20.1 for $\mathrm{Csn} 2 \mathrm{H}$, and 392.4 for Csn3. These values are in the range of chitosanases previously studied by our group except for $\mathrm{Csn} 3$ which is considerably higher.

\section{Biochemical characterization}

It was shown previously that the specific activity of chitosanases can vary according to the DDA of chitosan and that a single mutation could alter the substrate preference profile (Shimosaka et al. 1995; Lacombe-Harvey et al. 2013). Here, we tested two chitosans with DDA of 84.6 and $98.4 \%$, respectively (Fig. 3). Twelve replicas in two independent series of assays were performed. A statistical paired $t$ test was used to estimate if a given enzyme is significantly more active on higher DDA chitosan than on lower DDA chitosan. For $\mathrm{Csn} 1, \mathrm{Csn} 2 \mathrm{BH}$, and Csn2H, the activity increased significantly with the increase of DDA, a profile similar to that observed for wild-type CsnN174 (Lacombe-Harvey et al. 2013) which shares high amino acid sequence similarity with Csn1 and

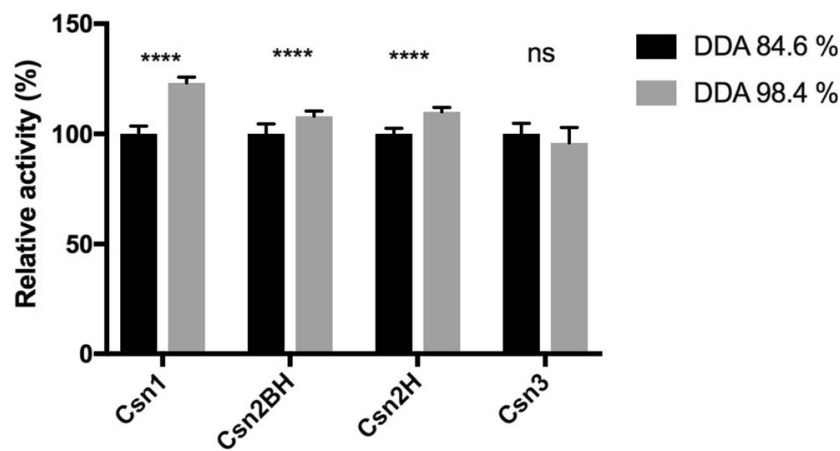

Fig. 3 Activity of chitosanases against chitosans of two different DDAs. For each enzyme, activity on lower DDA chitosan was taken as a reference $(100 \%)$. Results are averages of $12(\mathrm{Csn} 1, \mathrm{Csn} 2 \mathrm{H})$ or 18 $(\mathrm{Csn} 2 \mathrm{BH}, \mathrm{Csn} 3)$ replicates. $* * * *$ : activity on $98.4 \%$ chitosan significantly higher $(p<0.0001)$ than on $84.6 \%$ chitosan, ns: difference not statistically significant

Csn2. In contrast, Csn3 did not show any significant preference regarding DDA of chitosan substrate.

Measurement of kinetic parameters was performed with chitosan Sigma (Table 2). Substrate affinity, illustrated by $K_{\mathrm{m}}$, is roughly in the same range for Csn1, Csn2BH, and Csn2H but Csn 3 has significantly higher $K_{\mathrm{m}}$ (and, consequently, lower substrate affinity) than the other three enzymes. Kinetic study showed also that the very high specific activity of Csn3 is essentially explained by its rapid turnover.

\section{Activity at low temperatures}

Enzymes studied in this work originate from a soil organism and are more often exposed to cold conditions than to temperatures of $30-40{ }^{\circ} \mathrm{C}$ typically used in laboratories. However, cold temperatures were rarely applied in mostly biotechnologically oriented chitosanase studies (Johnsen et al. 2010). To evaluate how the chitosanases perform in cold environment, the relative loss of activity (compared with standard conditions at $37^{\circ} \mathrm{C}$ ) was measured for a series of temperatures (Fig. 4). It resulted that Csn3 is much more sensitive to low temperatures than the other three enzymes. In the lowest studied range ( 7 to $10^{\circ} \mathrm{C}$ ), Csn3 kept only $7 \%$ of activity (compared to standard conditions at $37^{\circ} \mathrm{C}$ ), while the other three enzymes had 23 to $27 \%$ of residual activity.

Table 2 Kinetic parameters of chitosanases

\begin{tabular}{llc}
\hline Enzyme & $K_{\mathrm{m}}\left(\mu \mathrm{g} \mathrm{ml}^{-1}\right)$ & $K_{\mathrm{cat}}\left(\mathrm{min}^{-1}\right)$ \\
\hline Csn1 & $21.9 \pm 3.7$ & 869 \\
Csn2BH & $15.8 \pm 1.9$ & 895 \\
Csn2H & $11.8 \pm 1.6$ & 660 \\
Csn3 & $93.8 \pm 12.5$ & 28,388 \\
\hline
\end{tabular}

Measurements were performed with chitosan from Sigma-Aldrich. Each concentration was assayed in six replicas 

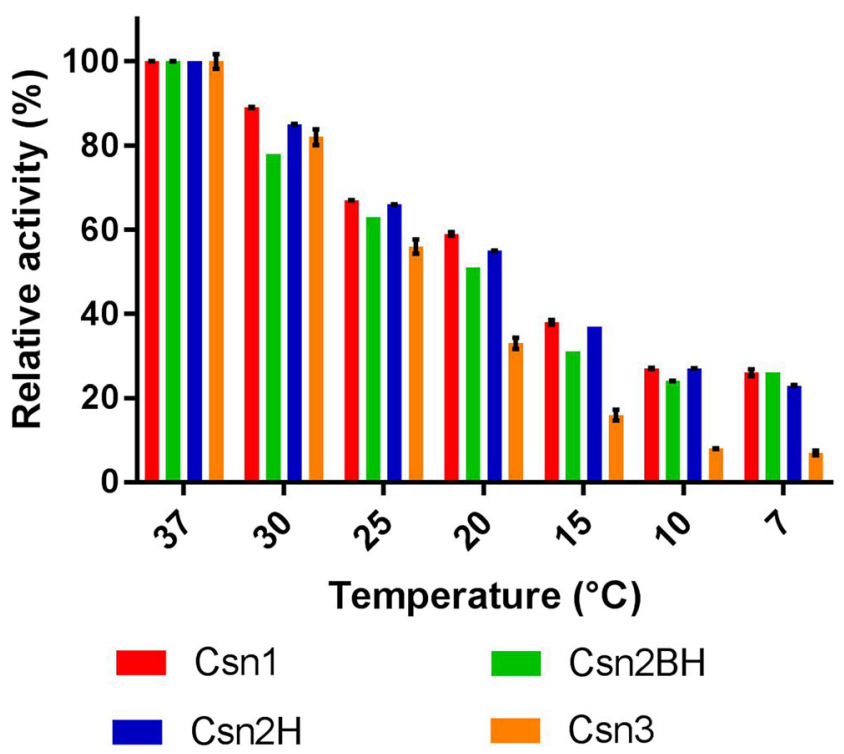

Fig. 4 Activity of chitosanases at low temperatures with standard substrate. Activity at $37^{\circ} \mathrm{C}$ was taken as a reference. Results are averages of six replicates

\section{Activity on chitosan complexed with polyphosphoric and humic acids}

K. setae is a soil organism and GH46 chitosanases are secreted outside the cell. In contrast with laboratory test conditions where chitosan is dissolved in buffer, enzymes in nature will have to act on undissolved chitosan or, perhaps more often, on chitosan being in interaction with a myriad of chemical compounds present in the soil environment. However, activity of chitosanases on complex substrates was rarely discussed in the literature (Sawaguchi et al. 2015). We then examined undissolved (i.e., freshly suspended) chitosan as substrate, as well as two compounds which are likely to form complexes with chitosan in soil.

Humic acid, universally present in soil, was shown to form complexes with chitosan (Wan Ngah and Musa 1998, Chen et al. 2011). The second tested compound is polyphosphate, a polymer commonly found in microbial cells (Achbergerová and Nahálka 2011). While synthesized and degraded intracellularly, it can be released in the environment as a result of cell lysis and form a complex with chitosan. Polyphosphatechitosan complex is also of interest as it was used in many biotechnologically or agriculturally oriented studies (Frossard et al. 1994; Jobin et al. 2005).

We tested several ratios of chitosan to polyphosphoric acid or humic acid at two $\mathrm{pH}$ values (4.5 and 5.5). Many of the tested conditions were either too severe for all enzymes (resulting in no measurable hydrolysis) or too mild (no differences among enzymes were observed and relative activity compared to that on sole chitosan was close to $100 \%$ ). We present, for both complexes, the conditions that allowed for best differentiation among the relative activities of the four studied chitosanases. In such conditions (Fig. 5) (see also "Materials and Methods" for details), Csn3 showed significantly less relative activity than the other enzymes. In addition, Csn2 had better or equal performance compared with Csn1. Furthermore, Csn2BH had significantly better activity on chitosan complexed with polyphosphoric acid (Fig. 4b) than $\mathrm{Csn} 2 \mathrm{H}$. On the other hand, the relative activity on undissolved chitosan was similar for all polypeptides (Fig. 4c). These results underline again the biochemical diversity among the four chitosanases.

\section{Discussion}

Heterogeneity in biochemical properties among GH46 chitosanases have been approached to some point in the literature. For instance, chitosanases from Streptomyces sp. N174 and Bacillus circulans MH-K1 differ by their preference to hydrolyze some linkages in chitosan. These differences have been explained by variations in tertiary structures (Saito et al. 1999). However, our work is focused on heterogeneity of GH46 chitosanases originating from the same one bacterial strain. Moreover, in most of the performed tests, at least one chitosanase stayed apart from the others. This is an indication that GH46 chitosanases are not biochemically homogenous despite their sequence similarity.

Csn1 was very similar to chitosanase CsnN174 from Streptomyces sp. N174 (actually shown to belong to the genus Kitasatospora by $16 \mathrm{~S}$ RNA sequencing; Blanchard et al. 2001). The high degree of amino acid sequence identity among them is reflected by similar kinetic properties and pronounced preference for high-DDA substrates.

Csn2 was found in two forms. The shorter $\mathrm{Csn} 2 \mathrm{H}$ comprising only the catalytic module was generated, possibly by proteolysis, from the full-length, bimodular Csn2BH which included a carbohydrate-binding module. Such proteolytic events targeting poorly structured segments, intercalating functional modules of proteins were observed in many instances (Watanabe et al. 1990; Gilkes et al. 1991). However, this is the first example of a well-documented cleavage of this kind in a GH46 chitosanase. In all our tests, the hydrolytic module itself, represented by $\mathrm{Csn} 2 \mathrm{H}$ polypeptide, gave results similar to Csn1. But, due to the presence of CBM, the full-length Csn2BH chitosanase stayed apart from its shorter form in assays with chitosan complexed with polyphosphoric acid. We then suggest that a possible function of the carbohydrate-biding module consists in increasing the accessibility of the chitosanase to its substrate in situations where chitosan is "hidden" by a complexing partner.

Csn3 is a case apart. In almost all our experiments, Csn3 behaved differently from the other three enzymes. It has much higher specific activity (possibly due to its much more rapid 
Fig. 5 Activity of chitosanases on a chitosan complexed with humic acid. b chitosan complexed with polyphosphoric acid. c undissolved chitosan. Activity at a given $\mathrm{pH}$ with standard substrate (chitosan Sigma) was taken as a reference. Identical letters indicate that the activities do not differ significantly, as concluded from the Tukey's multiple comparisons test. All assays were performed with six replicates
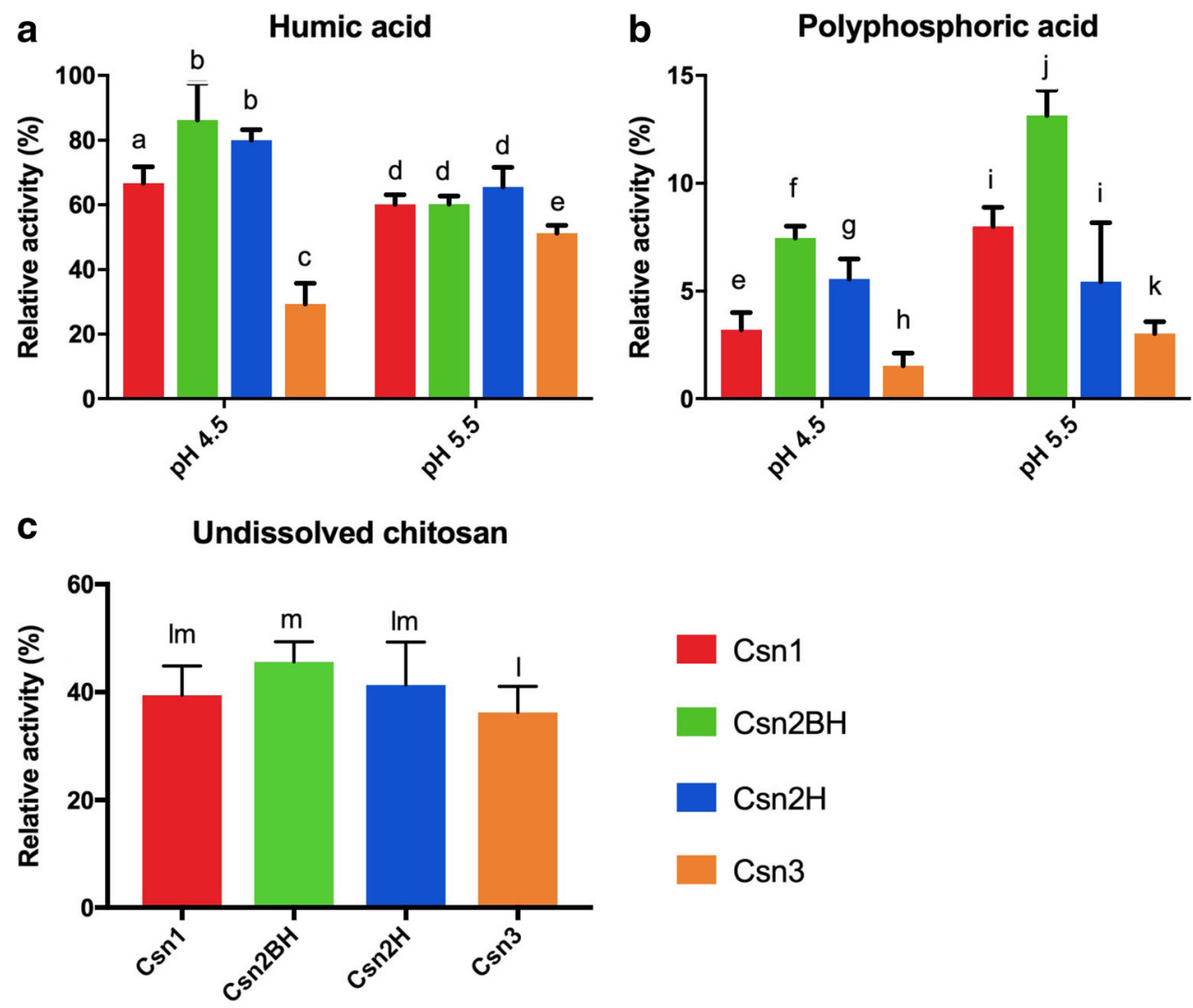

turnover), no substrate preference regarding the DDA of chitosan, and it loses its activity more rapidly in the cold and is less performant against chitosan complexed with polyphosphoric or humic acid. According to two large alignments of GH46 protein sequences (Takasuka et al. 2014; Viens et al. 2015b), Csn3 belongs to a separate cluster (group B) mostly populated by chitosanases from Gram + bacilli with $\mathrm{A}+\mathrm{T}$-rich genomes. However, there are no signs that the csn3 gene of $K$. setae could be laterally acquired from the Bacillus genus: DNA sequence analysis of $\operatorname{csn} 3$ with FramePlot (Ishikawa and Hotta 1999) revealed that it has a high $\mathrm{G}+\mathrm{C}$ content with maximization of $\mathrm{G}$ 's and $\mathrm{C}$ 's in the third position of codons, typical for actinobacteria but not for bacilli (data not shown).

The comparison of 3D models of Csn 1 and Csn3 chitosanases (Fig. 6a) highlights two major structural differences. First, the hinge segment linking the minor lobe and the major lobe close to the $\mathrm{N}$-terminus is shorter by two residues in Csn3 (Fig. 6b). The general acid catalytic residue (a glutamate) is localized in the proximity of this hinge segment (Marcotte et al. 1996; Lyu et al. 2014). Second, a large loop closing the substrate-binding cleft in the major lobe is longer by seven residues (Fig. 6c). An important arginine residue is localized in the immediate vicinity of this loop. Such structural differences could influence the function of these crucial residues. Also, a shorter hinge segment could influence the rotation of the minor lobe relative to the major lobe occurring during the process of substrate binding (Lyu et al. 2015).

Other differences among Csn3 and Csn1 as well as other deeply studied chitosanases from group A have possibly predictable consequences. Lyu et al. (2014, 2015) analyzed in detail the catalytic and substratebinding mechanisms of chitosanase OU01. Based on their work and on the large sequence alignment published previously (Viens et al. 2015b), we extracted a list of residues important for catalytic mechanism and substrate binding, as well as those contributing to the electronegativity of the substrate-binding cleft and the stability of inter-lobe interactions. We present (Table 3) the corresponding residues in $\mathrm{CsnN} 174, \mathrm{Csn} 1, \mathrm{Csn} 2, \mathrm{Csn} 3$, and the chitosanase from Bacillus subtilis (Rivas et al. 2000).

Data in Table 3 allow for several conclusions. While members of group A chitosanases are remarkably homogenous in their functional residues (with just a few minor substitutions for Csn2), Csn3 is quite different, having more similarity to $B$. subtilis chitosanase. However, residues directly involved in catalysis are strictly conserved in all five enzymes. Inside the set of residues involved in substrate binding, several substitutions are observed in Csn3; what could explain the differences in $K_{m}$ among Csn3 and Csn 1 or Csn2H? Nevertheless, the most drastic substitutions are observed for residues 
Fig. 6 Major structural differences between chitosanases Csn1 and Csn3. a Overall structure models obtained with ESyPred3D (Lambert et al. 2002) using the 4OLT file from Protein Data Bank (Lyu et al. 2014) as template, showing the minor (upper) lobe and the major (lower) lobe. Three residues directly involved in catalysis (Glu, Asp, Thr) are represented as balls and sticks. Green and red arrows indicate the segments detailed in sections $\mathbf{b}$ and $\mathbf{c}$, respectively. $\mathbf{b}$ comparison of hinge segments between the major and the minor lobe. c comparison between large loops in the major lobe. Graphics executed with the RasMol program (Sayle and Milner-White 1995)

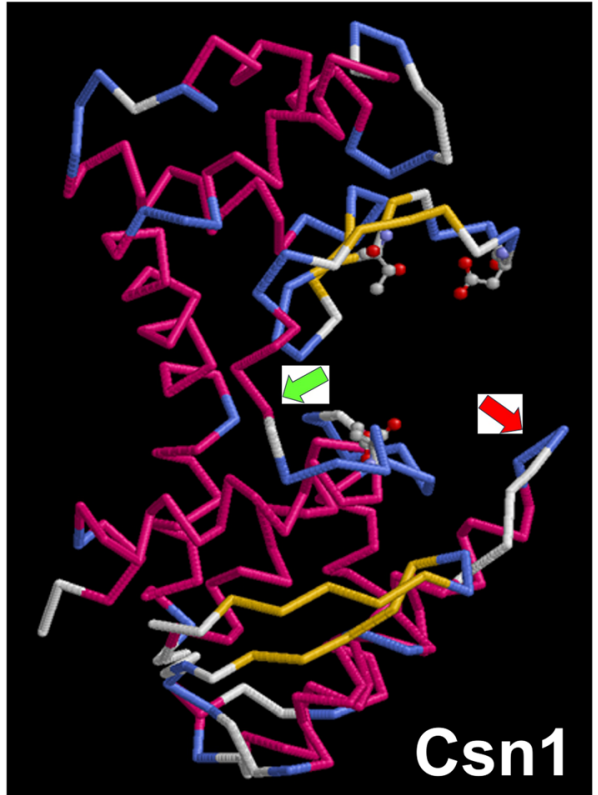

a
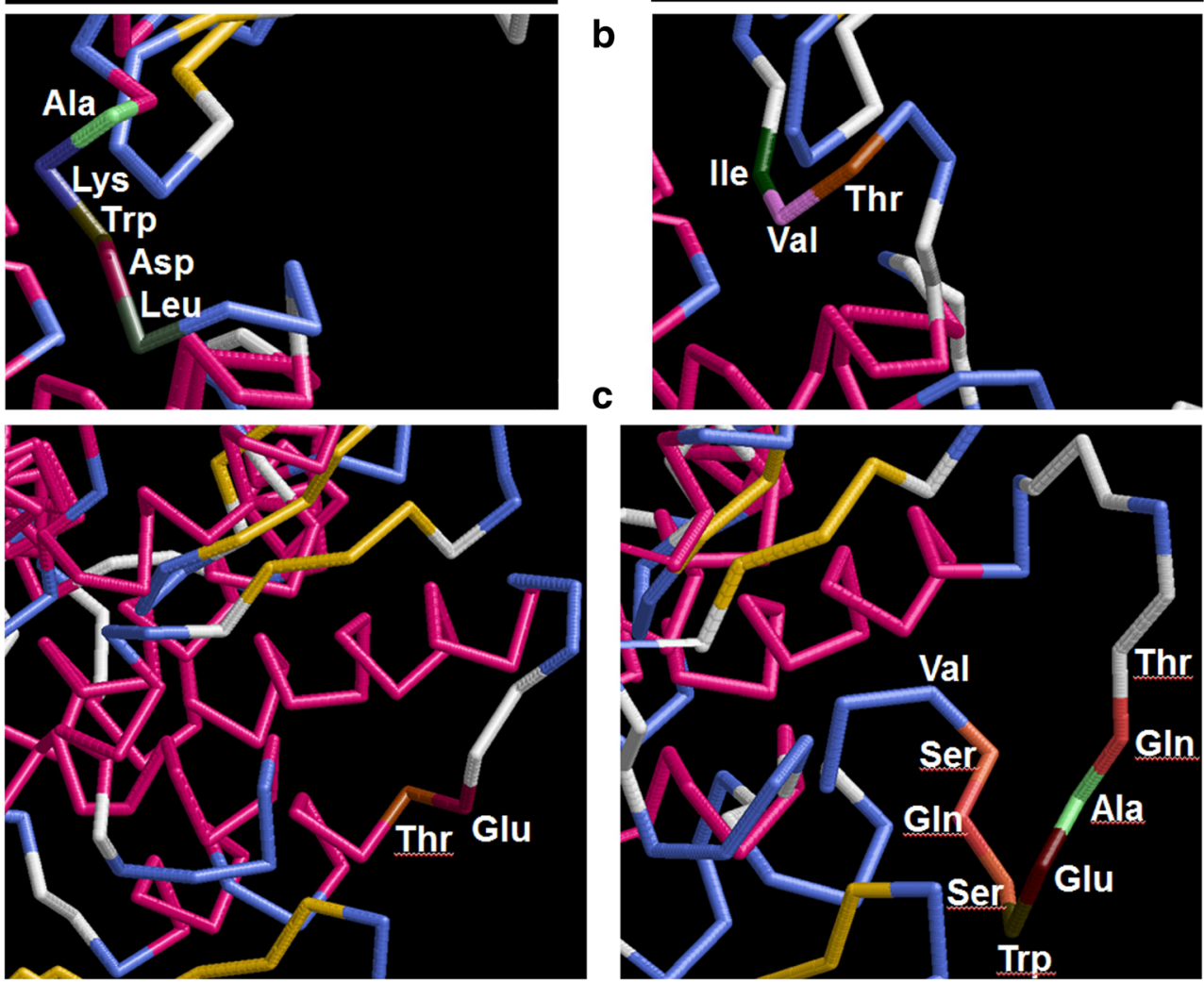
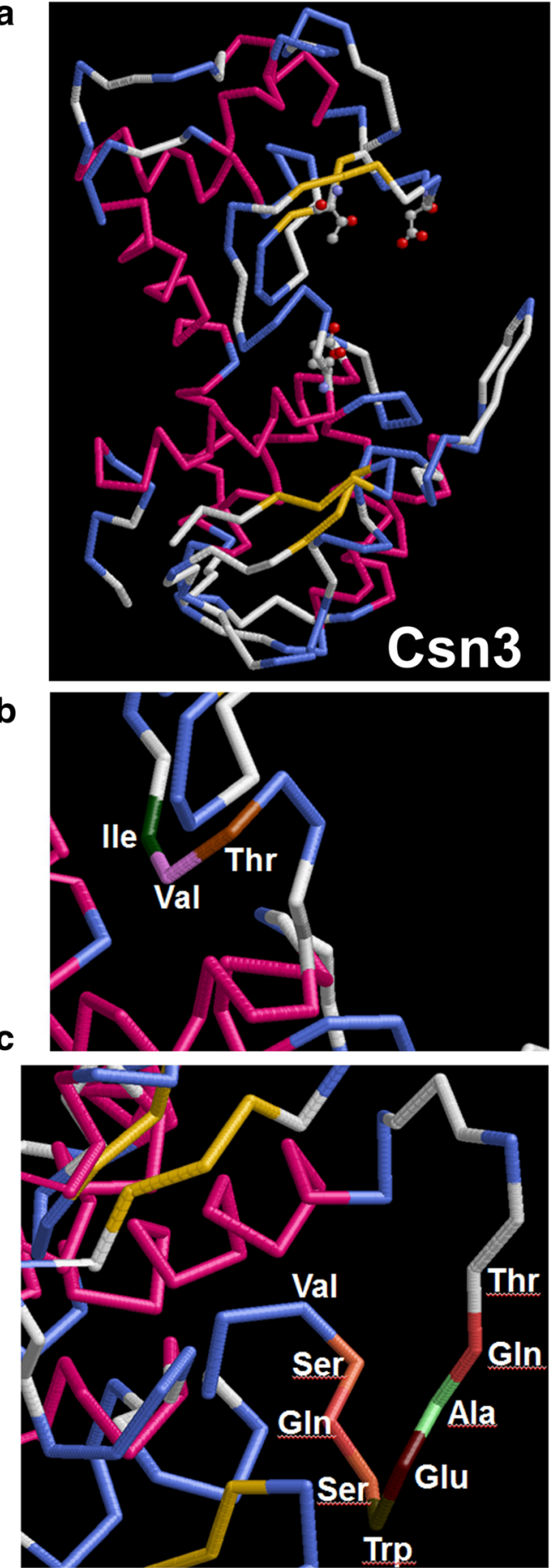

creating the electronegativity of the substrate-binding cleft or those involved in the inter-lobe stability. In Csn3 (and $B$. subtilis chitosanase), the substrate-binding cleft appears to be much less electronegative, including only two acidic residues compared with seven in group A enzymes. Lyu et al. (2015) mutated two glutamates from this set into alanine and the resulting enzymes gained enhanced specific activity. Thus, the decrease of electronegativity of the substrate-binding cleft can explain, at least partly, the higher specific activity (and turnover number) of Csn3 compared with Csn1 and Csn2H.

Finally, it was postulated that two interacting residues, Glu120 and Arg123 in OU01 chitosanase contribute to interlobe stability (Lyu et al. 2015). These residues are substituted by Gln and Glu, respectively in Csn3 suggesting a weaker interaction resulting in increased inter-lobe flexibility. The E120A mutation introduced by Lyu et al. (2015) aiming to disrupt this interaction resulted in an enzyme with enhanced 
Table 3 Correspondence of functional residues among chitosanases

\begin{tabular}{|c|c|c|c|c|c|c|}
\hline \multirow[t]{2}{*}{ Function } & \multicolumn{4}{|l|}{ group A } & \multicolumn{2}{|c|}{ group B } \\
\hline & OU01 chitosanase & CsnN174 & Csn 1 & Csn2 & Csn 3 & B.subt. \\
\hline \multicolumn{7}{|l|}{ Catalysis } \\
\hline General acid & Glu25 $(\mathrm{E} 25 \mathrm{~A}=\boldsymbol{\nabla})$ & Glu & Glu & Glu & Glu & Glu \\
\hline General base & Asp43 $(\mathrm{D} 43 \mathrm{~A}=\boldsymbol{\nabla})$ & Asp & Asp & Asp & Asp & Asp \\
\hline Water orientation & Thr48 & Thr & Thr & Thr & Thr & Thr \\
\hline \multicolumn{7}{|l|}{ Substrate binding } \\
\hline-3 , H-bond $\left(\mathrm{NH}_{2}\right)$ & His153 & His & His & His & His & His \\
\hline - 3, H-bond $(\mathrm{OH})$ & Pro155 & Pro & Pro & Pro & Asn & Asp \\
\hline$-3, \mathrm{H}-$ bond $(\mathrm{OH})$ & Thr58 & Thr & Thr & Thr & Asp & Thr \\
\hline - 2, H-bonds $(\mathrm{OH})$ & $\operatorname{Arg} 45$ & Arg & $\operatorname{Arg}$ & Arg & $\operatorname{Arg}$ & Arg \\
\hline - 2, H-bond $\left(\mathrm{NH}_{2}\right)$ & Asp60 $(\mathrm{D} 60 \mathrm{E}=\boldsymbol{\nabla})$ & Asp & Asp & Asp & Asp & Asp \\
\hline - 2, H-bond $\left(\mathrm{NH}_{2}\right)$ & Gly53 & Gly & Gly & Gly & Gly & Gly \\
\hline - 2, H-bond $\left(\mathrm{NH}_{2}\right)$ & Ile52 (through $\mathrm{H}_{2} \mathrm{O}$ ) & Ile & Ile & Ile & Ala & Ala \\
\hline-2 , H-bond $\left(\mathrm{NH}_{2}\right)$ & Val151 (through $\mathrm{H}_{2} \mathrm{O}$ ) & Val & Val & Val & Val & Ile \\
\hline - 2, H-bond $(\mathrm{OH})$ & Asp60 & Asp & Asp & Asp & Asp & Asp \\
\hline - 2, H-bond $(\mathrm{OH})$ & Thr58 & Thr & Thr & Thr & Asp & Thr \\
\hline - 1, H-bond $(\mathrm{OH})$ & Gly53 & Gly & Gly & Gly & Gly & Gly \\
\hline - 1, H-bond $(\mathrm{OH})$ & Ile52 & Ile & Ile & Ile & Ala & Ala \\
\hline - 1, H-bond $(\mathrm{OH})$ & Ile52 (through $\mathrm{H}_{2} \mathrm{O}$ ) & Ile & Ile & Ile & Ala & Ala \\
\hline - 1, H-bond $(\mathrm{OH})$ & Val151 (through $\mathrm{H}_{2} \mathrm{O}$ ) & Val & Val & Val & Val & Ile \\
\hline - 1, H-bond $\left(\mathrm{NH}_{2}\right)$ & His203 $(\mathrm{H} 203 \mathrm{~A}=\boldsymbol{\nabla})$ & His & His & His & Ser & His \\
\hline - 1, H-bond $(\mathrm{OH})$ & His203 $(\mathrm{H} 203 \mathrm{~A}=\mathbf{\nabla})$ & His & His & His & Ser & His \\
\hline$+1, \mathrm{H}$-bond $(\mathrm{OH})$ & Ala202 & Ala & Ala & Ala & Asn & Asn \\
\hline$+1, \mathrm{H}$-bond $\left(\mathrm{NH}_{2}\right)$ & Tyr37 & Tyr & Tyr & Tyr & Tyr & Tyr \\
\hline + 2, H-bond $(\mathrm{OH})$ & Ser27 & Ser & Ser & Ser & Gly & Gly \\
\hline$+3, \mathrm{H}-$ bond $(\mathrm{OH})$ & Ser27 & Ser & Ser & Ser & Gly & Gly \\
\hline$+3, \mathrm{H}$-bond $\left(\mathrm{NH}_{2}\right)$ & Asp235 & Asp & Asp & Glu & Ala & Tyr \\
\hline \multicolumn{7}{|c|}{ Cleft electronegativity } \\
\hline & Glu39 & Glu & Glu & Glu & Glu & Glu \\
\hline & Asp40 & Asp & Asp & Asp & Asn & $\operatorname{Arg}$ \\
\hline & Asp60 & Asp & Asp & Asp & Asp & Asp \\
\hline & Glu63 $($ E63A $=\mathbf{\Delta})$ & Glu & Glu & Asp & Lys & Glu \\
\hline & Glu120 $($ E120A $=\mathbf{\Delta})$ & Glu & Glu & Glu & Gln & Val \\
\hline & Glu200 & Glu & Glu & Glu & Pro & Pro \\
\hline & Asp235 & Asp & Asp & Glu & Ala & Tyr \\
\hline \multirow[t]{2}{*}{ Inter-lobe stability } & Arg123 & Arg & Arg & Arg & Glu & His \\
\hline & Glu120 $($ E120A $=\mathbf{\Delta})$ & Glu & Glu & Glu & Gln & Val \\
\hline
\end{tabular}

Numbering of residues and their function assigned for OU01 chitosanase as presented by Lyu et al. $(2014,2015)$. Corresponding residues in other chitosanases have been extracted from the structure-guided alignment in Viens et al. (2015b). In the substrate-binding section, the number of the subsite is indicated followed by the nature of interaction between amino acid and substrate. $(=\boldsymbol{\nabla})$ loss of activity after mutation into alanine; $(=\boldsymbol{\Delta})$ gain of activity after mutation into alanine as observed by Lyu et al. $(2014,2015)$ activity. Therefore, the increased inter-lobe flexibility provides a further explanation of the higher specific activity of Csn3. Clearly, group B chitosanases would merit more investigations of their structure-function relationships.

Members of the genus Kitasatospora were identified among the most abundant chitosan-degrading microorganisms at early stages of chitosan degradation in soil (Sawaguchi et al. 2015). The biochemical diversity of chitosanases such as observed in K. setae KM-6054 could contribute to such successful propagation. It remains to be investigated how such diversity could be exploited in biotechnological processes. 
Acknowledgements The authors thank professor Satoshi Ōmura, Nobel Laureate, for providing the strain of Kitasatospora setae. We thank Sylvain Lerat for the help with statistical analysis. This work was supported by a Discovery Grant from Natural Sciences and Engineering Research Council of Canada.

\section{Compliance with ethical standards}

Conflict of interest R. Brzezinski is a co-inventor of a patent describing the use of a $c s n R$-deleted strain for chitosanase production. Other authors declare no conflict of interest.

Open Access This article is distributed under the terms of the Creative Commons Attribution 4.0 International License (http:// creativecommons.org/licenses/by/4.0/), which permits unrestricted use, distribution, and reproduction in any medium, provided you give appropriate credit to the original author(s) and the source, provide a link to the Creative Commons license, and indicate if changes were made.

\section{References}

Achbergerová L, Nahálka J (2011) Polyphosphate: an ancient energy source and active metabolic regulator. Microb Cell Factories 10:63

Adachi W, Sakihama Y, Shimizu S, Sunami T, Fukazawa T, Suzuki M, Yatsunami R, Nakamura S, Takénaka A (2004) Crystal structure of family GH-8 chitosanase with subclass II specificity from Bacillus sp. K17. J Mol Biol 343:785-795

Bartnicki-Garcia S (1968) Cell wall chemistry, morphogenesis, and taxonomy of fungi. Annu Rev Microbiol 22:87-102

Blanchard J, Akimov VN, Neugebauer WA, Brzezinski R, Beaulieu C (2001) Taxonomic study on two chitosanolytic strains isolated from soil. In: RAA Muzzarelli (ed) Chitin Enzymology 2001. Atec Edizioni, Grottamare, pp 263-271

Bradford MM (1976) A rapid and sensitive method for the quantitation of microgram quantities of protein utilizing the principle of protein-dye binding. Anal Biochem 72:248-254

Brzezinski R (2011) Uncoupling chitosanase production from chitosan. Bioengineered Bugs 2(4):1-4

Chen J-K, Yeh C-H, Wang L-C, Liou T-H, Shen C-R, Liu C-L (2011) Chitosan, the marine functional food, is a potent adsorbent of humic acid. Mar Drugs 9:2488-2498

Dubeau M-P, Guay I, Brzezinski R (2011a) Modification of genetic regulation of a heterologous chitosanase gene in Streptomyces lividans TK24 leads to chitosanase production in the absence of chitosan. Microb Cell Factories 10:7

Dubeau M-P, Poulin-Laprade D, Ghinet MG, Brzezinski R (2011b) Properties of CsnR, the transcriptional repressor of the chitosanase gene, csnA, of Streptomyces lividans. J Bacteriol 193:2441-2450

Frossard E, Tekely P, Morel JL (1994) Chemical characterization and agronomic effectiveness of phosphorus applied as polyphosphatechitosan complex. Fertil Res 37:151-158

Gasteiger E, Hoogland C, Gattiker A, Duvaud S, Wilkins MR, Appel RD, Bairoch A (2005) Protein identification and analysis tools on the ExPASy server. In: Walker JM (ed) The proteomics protocols handbook. Humana Press (New York, NY), pp 571-607

Gilkes NR, Henrissat B, Kilburn DG, Miller Jr RC, Warren RAJ (1991) Domains in microbial $\beta$-1,4-glycanases: sequence conservation, function and enzyme families. Microbiol Rev 55:303-315

Gill SC, von Hippel PH (1989) Calculation of protein extinction coefficients from amino acid sequence data. Anal Biochem 182:319-326
Hamed I, Özogul F, Regenstein JM (2016) Industrial applications of crustacean by-products (chitin, chitosan, and chitooligosaccharides): a review. Trends Food Sci Technol 48:40-50

Hanahan D (1985) Techniques for transformation of E. coli. In: Glover DM (ed) DNA cloning: a practical approach, vol 1. IRL Press, Arlington, pp 109-135

Hoell IA, Vaaje-Kolstad G, Eijsink VGH (2010) Structure and function of enzymes acting on chitin and chitosan. Biotechnol Genet Eng Rev $27: 331-366$

Ishikawa J, Hotta K (1999) FramePlot: a new implementation of the frame analysis for predicting proteincoding regions in bacterial DNA with a high G+C content. FEMS Microbiol Lett 174:251-253

Ichikawa N, Oguchi A, Ikeda H, Ishikawa J, Kitani S, Watanabe Y, Nakamura S, Katano Y, Kichi E, Sasagawa M, Ankai A, Fukui S, Hashimoto Y, Kamata S, Otoguro M, Tanikawa S, Nihira T, Horinouchi S, Ohnishi Y, Hayakawa M, Kuzuyama T, Arisawa A, Nomoto F, Miura H, Takahashi Y, Fujita N (2010) Genome sequence of Kitasatospora setae NBRC $14216^{\mathrm{T}}$ : an evolutionary snapshot of the family Streptomycetaceae. DNA Res 17:393-406

Jobin G, Grondin G, Couture G, Beaulieu C (2005) Microscopic examination of chitosan-polyphosphate beads with entrapped spores of the biocontrol agent, Streptomyces melanosporofaciens EF-76. Microsc Microanal 11:154-165

Johnsen MG, Hansen OC, Stougaard P (2010) Isolation, characterization and heterologous expression of a novel chitosanase from Janthinobacterium sp. strain 4239. Microb Cell Factories 9:5

Kapaun E, Reisser W (1995) A chitin-like glycan in the cell wall of a Chlorella sp. (Chlorococcales, Chlorophyceae). Planta 197:577582

Lacombe-Harvey M-È, Fukamizo T, Gagnon J, Ghinet MG, Dennhart N, Letzel T, Brzezinski R (2009) Accessory active site residues of Streptomyces sp. N174 chitosanase-variations on a common theme in the lysozyme superfamily. FEBS J 276:857-869

Lacombe-Harvey M-Ė, Fortin M, Ohnuma T, Fukamizo T, Letzel T, Brzezinski R (2013) A highly conserved arginine residue of the chitosanase from Streptomyces sp. N174 is involved both in catalysis and substrate binding. BMC Biochem 14:23

Laemmli UK (1970) Cleavage of structural proteins during the assembly of the head of bacteriophage T4. Nature 227:680-685

Lambert C, Leonard N, De Bolle X, Depiereux E (2002) ESyPred3D: prediction of proteins 3D structures. Bioinformatics 18:1250-1256

Lever M (1972) A new reaction for colorimetric determination of carbohydrates. Anal Biochem 47:273-279

Liu S, Shao S, Li L, Cheng Z, Tian L, Gao P, Wang L (2015) Substratebinding specificity of chitinase and chitosanase as revealed by active-site architecture analysis. Carbohydr Res 418:50-56

Lombard V, Golaconda Ramulu H, Drula E, Coutinho PM, Henrissat B (2014) The carbohydrate-active enzymes database(CAZy) in 2013. Nucleic Acids Res 42:D490-D495

Lyu Q, Wang S, Xu W, Han B, Liu W, Jones DNM, Liu W (2014) Structural insights into the substrate-binding mechanism for a novel chitosanase. Biochem J 461:335-345

Lyu Q, Shi Y, Wang S, Yang Y, Han B, Liu W, Jones DNM, Liu W (2015) Structural and biochemical insights into the degradation mechanism of chitosan by chitosanase OU01. Bioch Biophys Acta 1850:19531961

Marcotte EM, Monzingo AF, Ernst SR, Brzezinski R, Robertus JD (1996) $\mathrm{X}$-ray structure of an anti-fungal chitosanase from Streptomyces N174. Nat Struct Biol 3:155-162

Ōmura S, Otoguro K, Nishikiori T, Oiwa R, Iwai Y (1981) Setamycin, a new antibiotic. J Antibiot 34:1253-1256

Pagé N, Kluepfel D, Shareck F, Morosoli R (1996) Effect of signal peptide alterations and replacement on export of xylanase A in Streptomyces lividans. Appl Environ Microbiol 62:109-114 
Pelletier A, Sygusch J (1990) Purification and characterization of three chitosanase activities from Bacillus megaterium P1. Appl Environ Microbiol 56:844-848

Rivas LA, Parro V, Moreno-Paz M, Mellado RP (2000) The Bacillus subtilis 168 csn gene encodes a chitosanase with similar properties to a Streptomyces enzyme. Microbiology 146:2929-2936

Roberts GAF (1992) Chitin chemistry. MacMillan, London

Saito J, Kita A, Higuchi Y, Nagata Y, Ando A, Miki K (1999) Crystal structure of chitosanase from Bacillus circulans $\mathrm{MH}-\mathrm{K} 1$ at $1.6-\AA$ resolution and its substrate recognition mechanism. J Biol Chem 274:30818-30825

Sanssouci E, Lerat S, Grondin G, Shareck F, Beaulieu C (2011) tdd8: a TerD domain-encoding gene involved in Streptomyces coelicolor differentiation. A Van Leeuw 100:385-398

Sawaguchi A, Ono S, Oomura M, Inami K, Kumeta Y, Honda K, Sameshima-Saito R, Sakamoto K, Ando A, Saito A (2015) Chitosan degradation and associated changes in bacterial community structures in two contrasting soils. Soil Sci Plant Nutr 61:471-480

Sayle R, Milner-White J (1995) RasMol: biomolecular graphics for all. Trends Biochem Sci 20:374-376

Schep GP, Shepherd MG, Sullivan PA (1984) Purification and properties of a $\beta$-1, 6-glucanase from Penicillium brefeldianum. Biochem J 223:707-714

Seghezzi N, Amar P, Koebmann B, Jensen PR, Virolle M-J (2011) The construction of a library of synthetic promoters revealed some specific features of strong Streptomyces promoters. Appl Microbiol Biotechnol 90:615-623

Shimosaka M, Nogawa M, Wang X-Y, Kumehara M, Okazaki M (1995) Production of two chitosanases from a chitosan-assimilating bacterium, Acinetobacter sp. strain CHB101. Appl Environ Microbiol 61: 438-442

Shinya S, Ohnuma T, Yamashiro R, Kimoto H, Kusaoke H, Anbazhagan A, Juffer AH, Fukamizo T (2013) The first identification of carbohydrate binding modules specific to chitosan. J Biol Chem 288:30042-30053

Sugita A, Sugii A, Sato K, Zhang X-Y, Dai A-L, Taguchi G, Shimosaka M (2012) Cloning and characterization of a gene coding for a major extracellular chitosanase from the koji mold Aspergillus oryzae. Biosci Biotechnol Biochem 76:193-195

Takasuka TE, Bianchetti CM, Tobimatsu Y, Bergeman LF, Ralph J, Fox BG (2014) Structure-guided analysis of catalytic specificity of the abundantly secreted chitosanase SACTE_5457 from Streptomyces sp. SirexAA-E. Proteins 82:1245-1257

Viens P, Dubeau M-P, Kimura A, Desaki Y, Shinya T, Shibuya N, Saito A, Brzezinski R (2015a) Uptake of chitosan-derived D-glucosamine oligosaccharides in Streptomyces coelicolor A3(2). FEMS Microbiol Lett 362:fnv048

Viens P, Lacombe-Harvey M-È, Brzezinski R (2015b) Chitosanases from family 46 of glycoside hydrolases: from proteins to phenotypes. Mar Drugs 13:6566-6587

Wan Ngah WS, Musa A (1998) Adsorption of humic acid onto chitin and chitosan. J Appl Polym Sci 69:2305-2310

Watanabe T, Oyanagi W, Suzuki K, Tanaka H (1990) Chitinase system of Bacillus circulans WL-12 and importance of chitinase A1 in chitin degradation. J Bacteriol 172:4017-4022

Yorinaga Y, Kumasaka T, Yamamoto M, Hamada K, Kawamukai M (2017) Crystal structure of a family 80 chitosanase from Mitsuaria chitosanitabida. FEBS Lett 591:540-547

Zhang X-Y, Dai A-L, Zhang X-K, Kuroiwa K, Kodaira R, Shimosaka M, Okazaki M (2000) Purification and characterization of chitosanase and exo- $\beta$-D-glucosaminidase from a koji mold, Aspergillus oryzae IAM2660. Biosci Biotechnol Biochem 64:1896-1902

Zitouni M, Fortin M, Thibeault J-S, Brzezinski R (2010) A dye-labelled soluble substrate for the assay of endo-chitosanase activity. Carbohydr Polym 80:521-524 